\title{
Parking System for Smart Cities
}

\author{
Mir Farazuddin Hamza, Soma Ram Ganesh, V.Sai Ganesh, Ahmed Ahtesham Uddin, Siddhartha Ghosh
}

\begin{abstract}
As we know due to increase in world population there is an increase in problems related to locomotive management, especially in urban areas. Being in contemporary world everyone faces a lot of problems every mundane morning with the traffic , which is inexorable. Even if the government becomes prodigal enough to spend on traffic management, it will not solve this problem easily. So the best solution to solve this is to solve the horrendous parking problem. Parking solution proposed by us is easy to implement. In this we have used sensors like IR sensor, RFID sensor to find vacant parking slot available. Here the driver can find the vacant slot using an application on mobile. This solution saves time and cost also it is tangible, flexible and also caters security. The application of our proposed system is best fit for places like shopping centre, High-tech business areas, public places etc.
\end{abstract}

Keywords: RFID tag, IR sensors, Internet of Things, Parking management, Blynk, WIFI.

\section{INTRODUCTION}

In modish world, people are yearning and excited on weekends to take their families off from home, there anxiety and eagerness turns into frustration, because of traffic jams, congestions and the main predicament is when it comes to parking. People mostly get irritated when they go for their shopping and be faced with a traffic jam in the car park. Both cost and time are of most importance to humans. It is very natural that business people to make their revenue try to allure the customers. Generally shopping malls, entertainment areas like theatres, exhibitions, food courts are the places where people visit [1].

Shopping places today do not merely provide a place for just buying and selling, but also it has become a place where many activities occur like banking service , kids play and gaming. Example in Malaysia, people generally visit shopping places for sight-seeing rather than spending time on shopping. [2]. Not only in places of shopping areas but also at airports are places were on average thousands of people visit. Therefore it is important that these places need to have proper perpetuation as concerned with the parking areas. So maintaining proper parking spaces is important in commodity areas of business.

Revised Version Manuscript Received on 16 September, 2019.

* Correspondence Author

Mir Farazuddin Hamza is student pursuing Bachelors in Electrical and Electronics Engineering in Vidya Jyothi Institute of Technology, Hyderabad, India Email: faraazhamza@gmail.com.

Soma Ram Ganesh is a student pursuing Bachelors in Electronics and Communication Engineering in Vidya Jyothi Institute of Technology, Hyderabad, India. Email: somaganesh47@gmail.com,

V. Sai Ganesh is a student pursuing Bachelors in Electrical and Electronics Engineering in Vidya Jyothi Institute of Technology, Hyderabad, India Email: saiganesh223468@ gmail.com,

Ahmed Ahtesham Uddin is a student pursuing Bachelors in Electrical and Electronics Engineering in Vidya Jyothi Institute of Technology, Hyderabad, India.. Email: a.ahtesham63@gmail.com,

Dr. Siddhartha Ghosh is a Professor in CSE Dept at Vidya Jyoth Institute of Technology, Hyderabad, India. Email: siddhartha@ vjit.ac.in
Maintaining proper space for parking along with robust security at places were mass crowd are present is important as traffic congestion or traffic jams probability of happening is very high and which may lead to security issues. To fathom this problem, we have expounded a solution for the parking problem by using sensors and internet of things concept

The main grain of writing this paper is to fathom parking problem and simultaneously explaining and expounding solution on it which scalable and flexible to implement. The solution mentioned in this paper is just a prototype.

In this section we expounded the importance of car parking especially in areas of shopping complex. In below section the paper will discuss about the general problems of parking and will then tell the proposed prototype solution.

\section{General PARKing COMPlication:}

Illegal parking is a general complication faced in urban environment. Roadside parking is a common phenomenon which reduces the traffic corridors meant for the efficient movement of automobiles. The resultant effect of such illegal parking is traffic congestion which also leads to delay in travelling time and increases the cost of travelling. Searching for vacant parking places especially at shopping malls that too at weekends is really frustrating. According to a research $86 \%$ of drivers have trouble with finding vacant parking spaces at shopping malls [3]. In busy cities it is often notable that due to Unauthorized and indiscriminate parking along streets is a serious impediment, seeing this it perceptible that it is caused due to meagreness of genuine parking management.[4] According to some research, people at weekends take an average time of more than 10 minutes to find a vacant place, as during weekends or holidays it is peak time. Approximately $66 \%$ public face this problem. [5]

\section{DETECTION POSSIBLE METHODS FOR FINDING VACANT SLOTS}

One of the technology that can be used for finding vacant parking slots is using vision based technology. CCTV cameras can be used to find the vacant by using image processing system. But detection system of cameras and image processing has drawbacks that is, it is mediocre to atmospheric or climatic conditions. Generally vision based parking detection systems has paramount complications which belie the vacant parking spot as occupied spot which may be caused due to vacillation of lighting conditions, shadow effects, distortion and occlusion effects. For instance in bright sunlight, cars in fair colour may belie the identification software with parking space as vacant, moreover it may conceivably detect an empty space as occupied space when dark-coloured cars a in shadowed slots. So the performance of identification may decrease with respect to light intensity [6]. 


\section{Parking System for Smart Cities}

Another way of identifying vacant space efficiently is using proper sensors. Sensors have made task much easier to complete. By fastidiously selecting proper sensors one can use it as a detection system. Factors of selection incorporate size, reliability, sensitivity, robust and its cost [7].

Examples of sensors are infrared sensors, ultrasonic sensors, RFID reader, RFID tags, underground detection sensors, humidity sensors etc. These sensors when connected with each other and then to an internet is called Internet of things, IOT is also defined as networking between different machines with help of Internet [8].

\section{Proposed Parking System Solution}

To solve the above problem, the proposed solution mentioned in the paper not only reduces traffic congestion, but also saves abundant of time. In this proposal IR sensors, Blynk server, Servo motors, LCD and microcontroller Node MCU and RFID have been used. The IR sensors are placed above parking slots - the sensors are fixed at the ceiling. When a car occupies a parking slot IR sensor detects its presence.

Its presence will be shown on the mobile application for end user that is to show the driver presence of parking slots, thereby saving a lot of time and also reducing the traffic congestion.

Firstly the user opens the application and searches for the parking slots availability, and books the slot. The user information is sent to server (in figure 1 as shown in the diagram the arrives at the gate where RFID module is present on left side of the car) where all the information is stored. As the proposed solution is for complexes, for ensuring security at parking entrance the user has to swipe his RFID tag to the RFID reader.

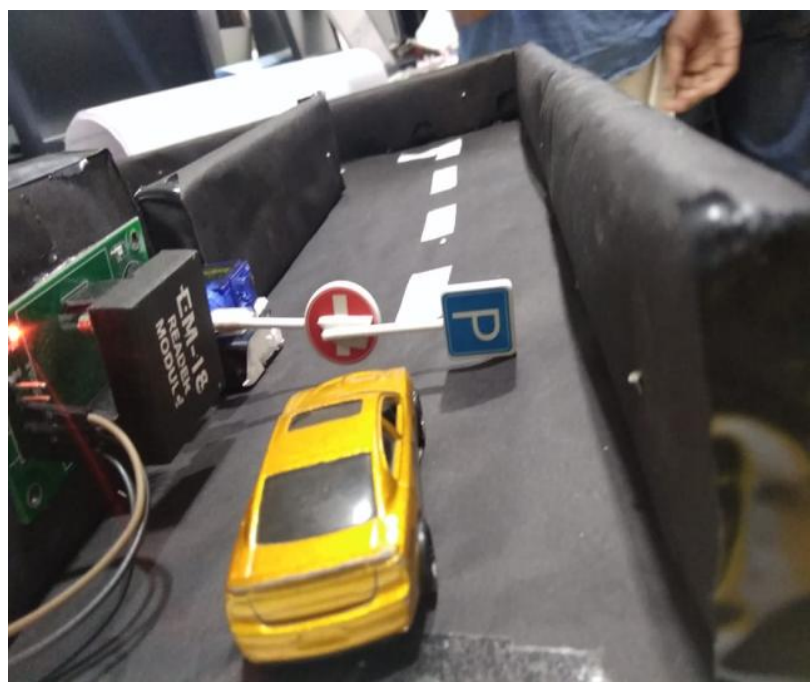

Fig 1. Car near entrance

When the user swipes his card, the user details are cross-checked with the stored details like name and vehicle number in database. If the details matches than it means that user has booked parking slot, and so the gate opens and duration of stay is recorded. When time is out, the user is notified with SMS or mail. Below is the figure 2 which shows car in the parking slot.
To summarize our solution a figure 2 is shown below to expound it. This mentioned solution of ours is just a working prototype.

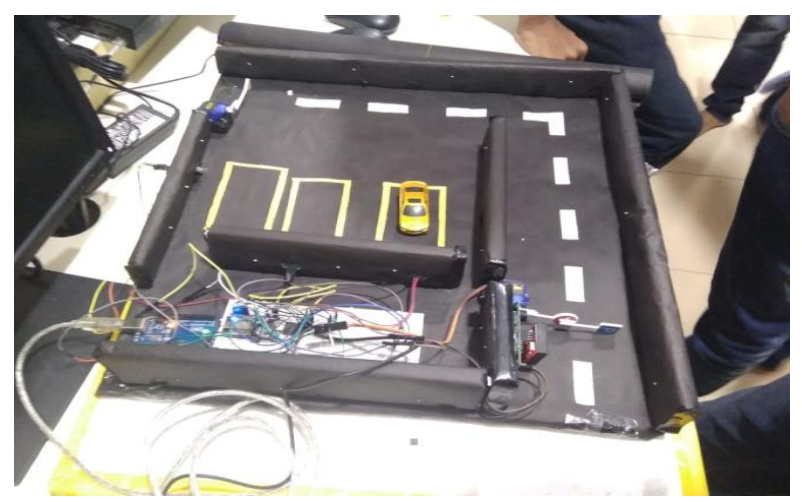

Fig 2. Car in parking slot

The given below figure 3 demonstrates the interface between the microcontroller and the BLYNK server car arrives at parking slot and how the IR sensor detects the presence of car and send information to mobile application through node mcu the microcontroller then to BLYNK server and then to mobile application.

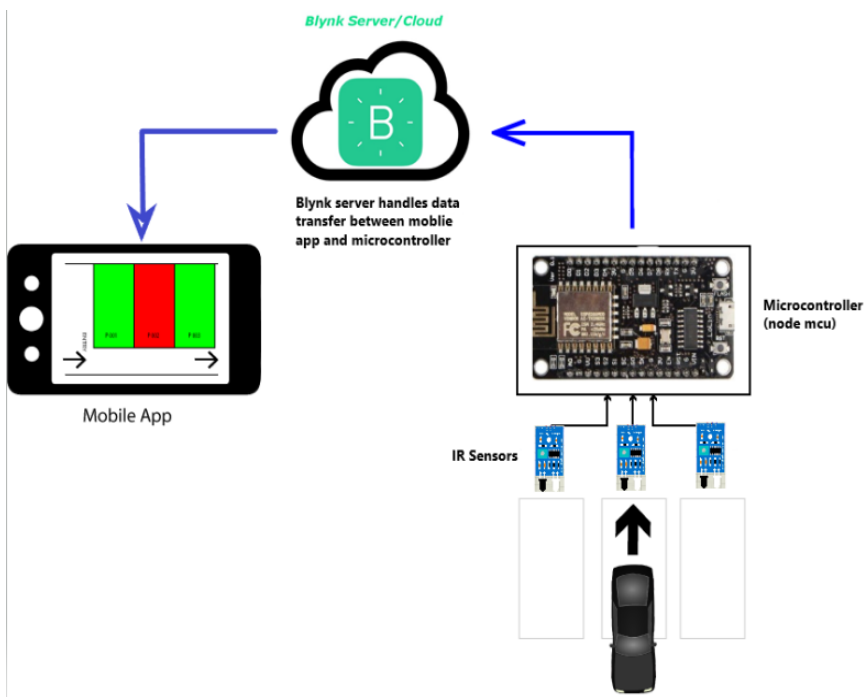

Fig 3. Workflow Diagram

In below figure 4 it describes the procedure of booking parking slot. Here the driver books a slot. It then ask for payment of money through online so as to confirm the booking. The user name, time of entry and his car detains are stored in the BLYNK server. The driver then proceeds to park his car the slot. The time of entry is recorded at entrance of parking areas. When the allotted time ends the driver gets notification to un-park his car. 


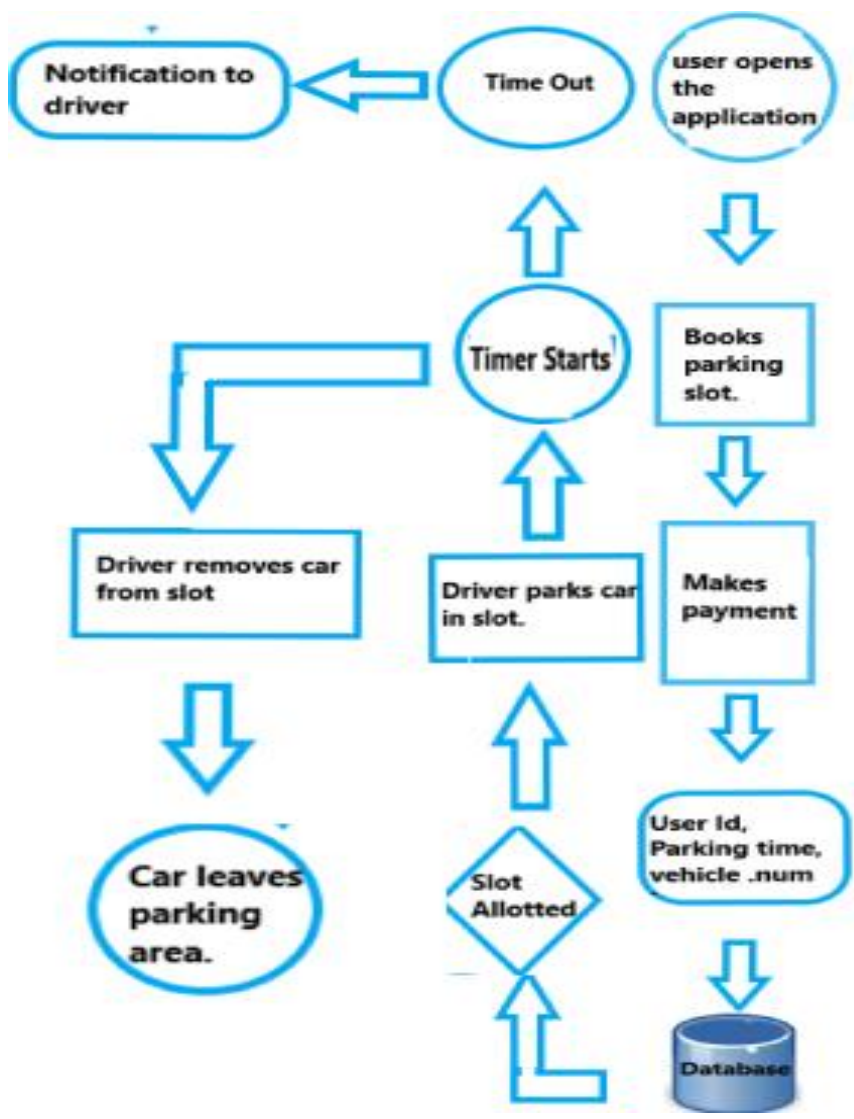

Fig 4. Flow chart of smart parking

Components Used:

NodeMCU: It is microcontroller with wifi system. It's a development kit and open- source frame work developed for IOT platform. Different applications can be built on this using different IDE , of which Arduino development environment is easy to use.[9]

Servo motor: It is a rotatory electronic device with sensor in it that controls rotation or linear motion of motor connected to it. It has an accurate control of velocity or acceleration and also motion of the linear motion [10].In our project we have used DC servomotor, which have operating voltage range between 5-15 volts.

IR sensors: It is an electronic device which emits infrared radiations to detect the presence of an object. has built in IR transmitter and IR receiver which emits IR radiation and looks for reflected IR radiation to detect presence of any obstacle .It is effective even in presence of ambient light or complete darkness.[11]

Cloud: The cloud acts as a database for keeping all the information of drivers which incorporates parking time, payment details, exit time, entry time, mode of payment of the users and date. On the cloud BLYNK server is hosted. Using this cloud any number of end-users data can be stored in it anytime without any interruption. For ensuring safety the data is continuously backed up, in case any system failure occurs.

RFID: It comprises of a reader and a tag. The tag is generally attached to object. When the tag is bought near the reader, both of them start to communicate with each other using electromagnetic fields. The tag contains electronically stored data. [12]

Mobile application: The mobile application has been used to connect the user with parking system.. The format of transfer of data takes place in JSON between the mobile application and the BLYNK server. Through a secure channel the application is connected to BLYNK server with two factor authorization.

To make the application run on both the Android platform and IOS platform Apache Cordova is used with source code same for both the platforms. The application is for end users to cater them the information of availability of parking slots in the parking area and also helping the users to book the slots. For ensuring proper communication between the application and BLYNK server both of these are to be subscribed on BLYNK server.

The given below figure is schematic design of the sensors connected to the microcontroller.

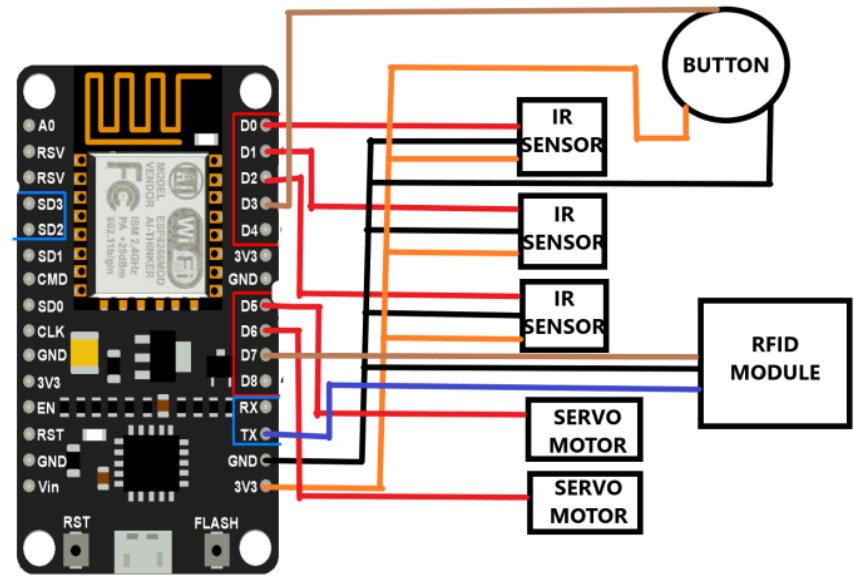

FIG 5: BLOCK DIAGRAM

\section{EXPERIMENTAL RESUltS}

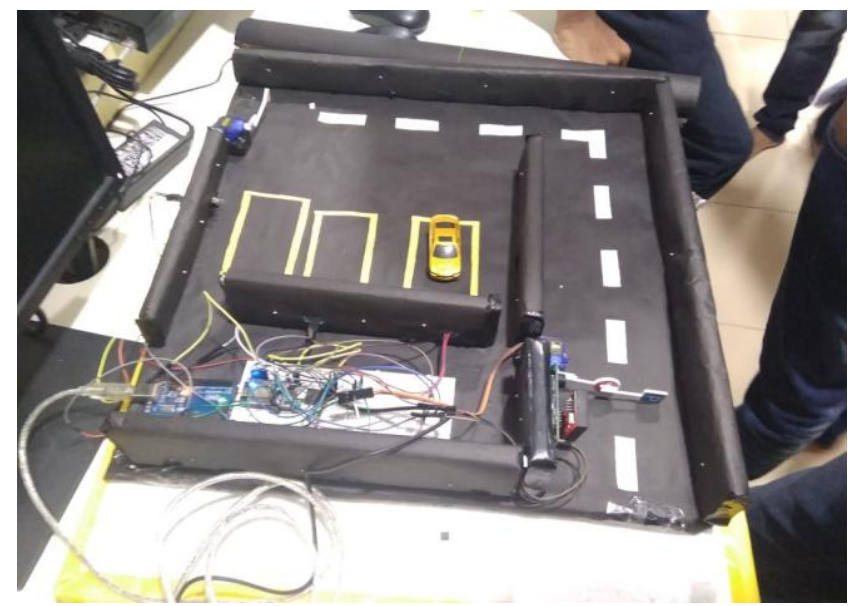

Fig 6: Experiments results

The above is experimental result of the project, in which it shows that after booking of slot through application, the car enters the parking area through servo-motor where he swipes his RFID tag to the reader. If his information matches then servo motor will open. And now with help of the mobile application he finds his parking slot and parks his car.

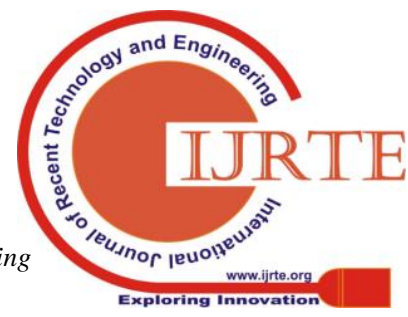




\section{Conclusion}

The hand-out of this research was to discuss on the importance of solving the parking problem, solution discussed in this paper exploits technologies for finding empty lots with help of Blynk server, it is also easy to implement and efficient in finding vacant places for frustrated people. This decreases time and cost of the public, also this project can further be enhanced by incorporating pre-booking system, parking fee system, GPS system etc.

\section{REFERENCES}

1. Belief, Attitude, Intention, and Behavior: An Introduction to Theory and Research. Book by Martin Fishbein.

2. SPS architecture using Ultrasonic detector. Authored by Amin Kianpisheh, Norlia Mustaffa, Pakapan Limtrairut and Pantea Keikhosrokiani.

3. "User Behavioral Intention toward Using Smart Parking System", Proceeding of ICIEIS, (2011) Kuala Lumpur, Malaysia, pp. 732-747.

4. African Journal of Engineering Research Vol. 1(2), pp. 40-48, May 2013 Full Length Research Paper.

5. Litman T, 2007. Parking Management: Comprehensive Implementation Guide, VTPI. (Available at www.vtpi.org/parkmancom.pdf).

6. C. C. Huang and S. J. Wang, "A Hierarchical Bayesian Generation Framework for Vacant Parking Space Detection", Circuits and Systems for Video Technology, IEEE Transactions, (2001), pp. 1.

7. "Machine-vision Systems for Intelligent Transportation Systems", IEEE, vol. 13, (1998), pp. 24-31.

8. 'What Internet of things needs to become a reality'.Kaivan Karimi, Gary Atkinson. White Paper, FreeScale and ARM , 1-16,2013.

9. International Journal of Computer Science and Mobile Computing, IJCSMC, Vol. 2, Issue. 5, May 2013, pg.417 - 424.

10. Latika Becker "Influence of IR sensor technology on the military and civil defence", Proc.SPIE 6127, Quantum Sensing and Nanophotonic Devices III, 61270S(28 February 2006); doi:10.1117/12.640529; https://doi.org/10.1117/12.640529.

11. Robust speed control of DC servomotors using modern two degrees-of-freedom controller design, IEEE Transactions on Industrial Electronics (Volume: 38 , Issue:5, Oct 1991).

12. An Introduction to RFID Technology, January-March 2006, pp. 25-33 , vol.5, DOI bookmark:10.1109/MPRV.2006.2.

\section{AUTHORS PROFILE}

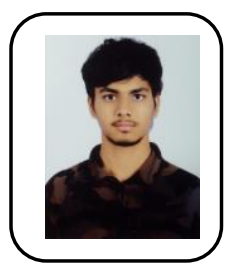

Mir Farazuddin Hamza is student pursuing Bachelors in Electrical and Electronics Engineering in Vidya Jyothi Institute of Technology, Hyderabad, India. His interests are in Internet of Things Applications, Data Science and Machine Learning.

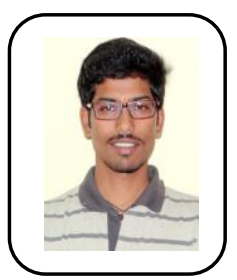

Soma Ram Ganesh is a student pursuing Bachelors in Electronics and Communication Engineering in Vidya Jyothi Institute of Technology, Hyderabad, India. His interests are in Internet of Things Applications, Electronics, Data Science and Machine Learning.

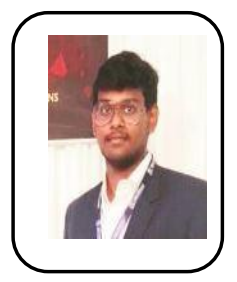

V. Sai Ganesh is a student pursuing Bachelors in Electrical and Electronics Engineering in Vidya Jyothi Institute of Technology, Hyderabad, India. His interests are in Internet of Things Applications, Machine Learning.

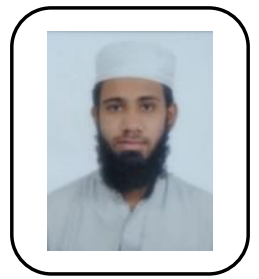

Ahmed Ahtesham Uddin is a student pursuing Bachelors in Electrical and Electronics Engineering in Vidya Jyothi Institute of Technology, Hyderabad, India. His interests are in Internet of Things Applications, Machine Learning.

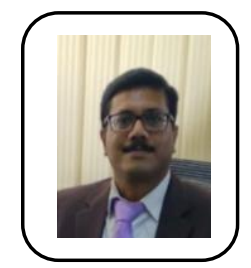

Dr. Siddhartha Ghosh is a Professor in CSE Dept at Vidya Jyothi Institute of Technology with 18 years of teaching and research experience. His areas of interests are AI, ML, IoT, Big Data, NLP etc. 